\title{
Overexpression of Arabidopsis FT gene in apple leads to perpetual flowering
}

\author{
Norimitsu Tanaka' ${ }^{1}$ Ayano Ureshino ${ }^{2}$, Narumi Shigeta ${ }^{3}$, Naozumi Mimida ${ }^{2, a}$, \\ Sadao Komori ${ }^{3}$, Sae Takahashi ${ }^{2}$, Yuki Tanaka-Moriya ${ }^{2}$, Masato Wada ${ }^{2, *}$ \\ ${ }^{1}$ Faculty of Agriculture and Life Science, Hirosaki University, Hirosaki, Aomori 036-8561, Japan; ${ }^{2}$ Apple Research Station, \\ National Institute of Fruit Tree Science, NARO, Shimokuriyagawa, Morioka, Iwate 020-0123, Japan; ${ }^{3}$ Faculty of Agriculture, \\ Iwate University, Ueda, Morioka, Iwate 020-8550, Japan \\ *E-mail: mwada@affrc.go.jp Tel: +81-196-45-6155 Fax:+81-196-41-3819
}

Received July 4, 2013; accepted September 12, 2013 (Edited by T. Mizoguchi)

\begin{abstract}
Transgenic apple plants that overexpressed Arabidopsis FLOWERING LOCUS T (FT) under the control of the rolC promoter showed early flowering, while the introduction of FT driven by the $35 \mathrm{~S}$ promoter induced flower development directly from transgenic apple callus in vitro, but vegetative growth was not maintained and the explant died. GFP-FT fusion proteins were detectable in transgenic apple tissues but never caused early flowering in the transformants. Under the control of the rolC promoter, the fused protein was localized in vascular tissues and fluorescence was detectable in companion cells in the stem and petiole. The transgenic apple lines that expressed AtFT driven by the rolC promoter showed differences in inflorescence architecture and floral organ number from those typical of nontransformed apple. Flowers of transgenic apple lines often contained more numerous petals, fewer stamens, and no pistils, and the pollen grains were incapable of germinating. The transgenic apple lines showed perpetual flowering without the requirement for low temperature and obvious photoperiodism. The expression patterns of six floral meristem identity genes and floral organ genes in flowers of transgenic apple lines were investigated. Among the floral meristem identity genes, expression of MdFT2 was suppressed and that of AFL2 was dramatically enhanced in the transformants. Of the floral organ genes, expression of MdMADS13, which functions as a class B gene, was unchanged from that of the flower of wild type one, whereas expression of $M d M A D S$-NB, a possible class $\mathrm{C}$ gene, was suppressed.
\end{abstract}

Key words: Apple, flowering, FT, MADS, rolC promoter.

Apple (Malus $\times$ domestica Borkh.) is among the most popular fruit trees and is an important commercial fruit crop in temperate areas of the world. Many researchers have sought to improve fruit size, fruit skin color, disease resistance and taste. Molecular-based breeding techniques have been applied increasingly to woody plants. In many cases, research based on model plants, such as Arabidopsis and rice, has been done woody plants because both herbaceous and woody plants share biological and developmental phenomena that are often regulated by the same molecular mechanism. However, woody plants are distinct from herbaceous plants in possessing a much longer juvenile period in their life history. Herbaceous plants tend to adjust their life history by adaptation to environmental conditions. Conversely, woody plants depend on internal physiology, nutrition and phytohormones to regulate their development.

The multi-year delay in the onset of flowering in woody plants hampers their breeding. To shorten the long generation time, researchers have sought to identify flowering genes in apple. The Arabidopsis LEAFY gene (Weigel and Nillson 1995), a floral meristem identity gene, was the first transgene reported to cause extreme flowering precocity in poplar. A similar approach was applied for transformation of apple with $L E A F Y$ and the apple ortholog $A F L$ gene, respectively (Flachowsky et al. 2010; Wada et al. 2002). Each apple transformant that overexpressed the respective transgene did not show early flowering, but instead showed suppression of vegetative growth. Thus the apple $L E A F Y$ ortholog did not induce flowering. In situ hybridization experiments showed that AFL2 was expressed in the shoot apex, floral primordia and floral organs (Mimida et al. 2011), and therefore apple $L E A F Y$ orthologs are hypothesized to play a role in floral organ development.

The Arabidopsis TERMINAL FLOWER1 (TFL1) gene functions to maintain vegetative growth and behaves as an antagonist of the FT gene in flowering (Hanano 
and Goto 2011). The TFL1 loss-of-function mutant, $t f l 1$, showed formation of a determinate inflorescence and early flowering in Arabidopsis. The corresponding gene in tomato, SELF-PRUNING, and in snapdragon, CENTRORADIALIS, has the same functions in vegetative and reproductive growth (Cremer et al. 2001; Pnueli et al. 1998). Members of the Rosaceae family have conserved orthologs of TFL1 (Chen et al. 2013; Iwata et al. 2012; Mimida et al. 2012), which are functionally similar to TFL1. A TFL1-like gene family is found in apple (Kotoda and Wada 2005; Mimida et al. 2009, 2012), which might function redundantly as a flowering repressor and regulator of vegetative growth. Suppression of MdTFL1 expression by antisense oligomers or gene silencing results in induction of precocious flowering in transgenic apples (Flachowsky et al. 2012; Kotoda et al. 2006) and simultaneously reduces vegetative growth. These results support the contention that apple MdTFL1 is an ortholog of Arabidopsis TFL1.

The FLOWERING LOCUS T (FT) gene of Arabidopsis is well known as a floral activator and the coding protein is transported from leaves to the shoot apex as a floral initiation signal, termed 'florigen.' Orthologs of FT in other herbaceous and woody plant species are highly conserved and promote flowering in the respective plants (Böhlenius et al. 2006; Corbesier et al. 2007; Lifschitz and Eshed 2006; Tamaki et al. 2007). Two FT homologs, $M d F T 1$ and MdFT2, have been isolated from apple. The two genes are expressed mainly in floral tissues and at different stages of flower development, which suggests that the two genes play different roles in the onset and maturation of apple flowers (Kotoda et al. 2010). Transgenic apple plants that express 35S::MdFT1 show early flowering and promotion of flower development within a year after transformation (Kotoda et al. 2010; Tränkner et al. 2010). Similarly strong promotion of flowering by $F T$ overexpression has been reported for the woody plants poplar, citrus, pear and plum (Endo et al. 2005; Hsu et al. 2006; Matsuda et al. 2009; Srinivasan et al. 2012). These results indicate that $F T$ genes from woody plants are highly conserved as a floral activator. Pear and plum plants transformed with $F T$ from other species show also early flowering. In apple plants that express 35S::MdFT, the induction of flowering is not maintained in subsequent years after transformation. The transformants set many flowers in vitro and when grown in pots in the first year after transformation, but in the following year show vigorous vegetative growth and gradually reduced flower numbers. Expression of the transgene in transformants that bear no flowers is detectable by northern analysis several years after transformation, which suggests that the transgene has a possible repressive impact on the induction of flowering. Pear transformants that express $35 \mathrm{~S}:$ : CiFT show similar attenuation of flowering. However, citrus transformants that express 35S::CiFT show perpetual flowering each year (Nishikawa and Endo personal communication). Transgenic apple plants that express 35S::MdFT2 also show early flowering and similar attenuation of flowering to that of transformants overexpressing MdFT1.

$F T$ genes are indicated to have multifaceted roles in plant developmental processes in addition to promotion of flowering (Pin and Nilson 2012), which indicates that FT proteins or RNA transcripts might have unknown functions. In this article, we report that apple transformed with the A. thaliana FT (AtFT) gene showed markedly earlier flowering under restricted expression and that the expression patterns of apple floral genes were severely affected.

\section{Materials and methods}

\section{Plant material}

The apple semi-dwarfing rootstock cultivar 'JM2' (Malus prunifolia (Wild.) Borkh. 'Seishi' $\times$ M. pumila Mill. var. paradisiaca Schneid. 'M9') was cultured in vitro and leaflets were used in transformation experiments as described previously (Wada et al. 2009).

\section{Vector construction for apple transformation}

Arabidopsis FT cDNA was amplified from flower buds of Arabidopsis thaliana Columbia strain by PCR using primers designed on the basis of nucleotide sequence data (GenBank accession no. AB027504). The FT cDNA was amplified with the primers 5AtFTX and 3AtFTS (Table 1), which contained

Table 1. Primer sets for gene cloning and quantitative real-time PCR analysis.

\begin{tabular}{lc}
\hline \multicolumn{1}{c}{ Primer } & Oligonucleotides $\left(5^{\prime} \rightarrow 3^{\prime}\right)$ \\
\hline $\begin{array}{l}\text { Gene cloning } \\
\text { 5AtFTX }\end{array}$ & ATTCTAGACAATCAACACAGAGAAACCACC \\
3AtFTS & ATGAGCTCATCATCACCGTTCGTTACTCG \\
RO5 & AAAGCTTAAAGTTGGCCCG \\
RO3 & ATTCTAGAAACAAAGTAGGAAACAGG \\
tF5 & GTCTATAAATATAAGAGACC \\
tF5X & AATCTAGAT GTCTATAAATATAAGAGACC \\
tF3 & AAGTCTTCTTCCTCCGC \\
tF3N & ATCCATGGC AAGTCTTCTTCCTCCGC \\
Quantitative RT-PCR & \\
MdFT1F & CTAGACCTGATATTGGTGGA \\
MdFT1R & CCAATTGGCGAAACACCACC \\
MdFT2F & CTAGAGTTGATACTGGGGGT \\
MdFT2R & CCAATTGGCGAAACAGCACA \\
MdMADS5F & TGTCTAAACAATGGGGGGAC \\
MdMADS5R & TCATATAATGGTTCCAGAGTC \\
MdMADS13F & TATTAAGGTCACTTATAACTGC \\
MdMADS13R & CAAACCCACAAGCAACAAGG \\
MdMADS-NBF & AGCAAACATGGTTTCTGTGC \\
MdMADS-NBR & TCTGGCTAAAGAAATTGCGC \\
AFL2F & GAGAGAGTTTGAGCAAACTAA \\
AFL2R & AGTAGATCATAACAGGATCCTAA \\
\hline &
\end{tabular}




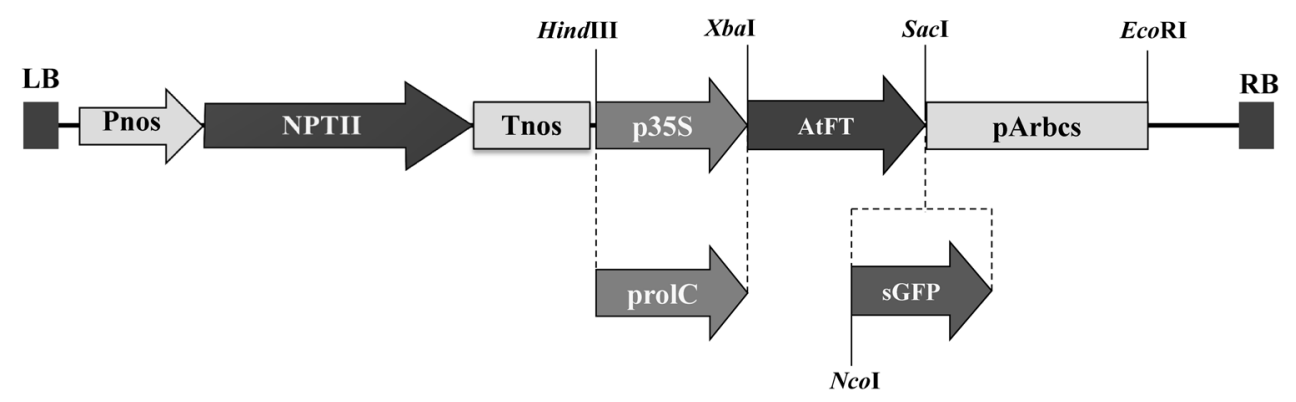

Figure 1. Schematic representation of the transformation vectors pSM35S::AtFT, pSMrolC::AtFT, pSM35S::AtFT:GFP, and pSMrolC::AtFT:GFP. Arabidopsis AtFT cDNA was inserted into the Xba I and Sac I sites of the binary vector pSMAK251, which was designated pSM35S::AtFT, or the Agrobacterium rhizogenes rolC promoter was inserted at the same sites and the resulting construct was designated pSMrolC::AtFT (broken line). The same vectors with sGFP ligated after AtFT in the frame were designated pSM35S::AtFT:GFP and pSMrolC::AtFT:GFP, respectively (broken line). Pnos, nopaline synthase promoter; NPTII, neomycin phosphotransferase II; Tnos, terminator of nopaline synthase; p35S, Cauliflower mosaic virus $35 S$ promoter; prolC, A. rhizogenes rolC promoter; AtFT, Arabidopsis FLOWERING LOCUS T; sGFP, green fluorescent protein; pArbcs, terminator of Rubisco; LB, left border; RB, right border. Each restriction enzyme site is indicated by bold letters.

the XbaI and SacI restriction enzyme sites, respectively. The amplified DNA fragment was subcloned into the EcoRV site of the pBlueScript SKII+ vector (Stratagene, La Jolla, CA, USA) and transformed into Escherichia coli strain $\mathrm{DH} 5 \alpha$. After white/blue colony selection, five clones from white colonies were fully sequenced in both directions, which showed that the nucleotide sequence of all clones was identical to that of the Arabidopsis FT cDNA. The FT plasmid was digested with $X b a \mathrm{I}$ and SacI and inserted into the corresponding site of the pSMAK 251 binary vector (Yamashita et al. 1995). The vector containing the sense-oriented FT gene under the control of the 35 S promoter was designated pSM35S::AtFT (Figure 1). The rolC::Hd3a:GFP binary vector derived from the pBI101 vector (Tamaki et al. 2007) was obtained from Associate Professor Shuji Yokoi, Iwate University, Japan. The rolC promoter (Matsuki et al. 1989; Sugaya and Uchimiya 1992) (GenBank accession no. DQ160187) was amplified by PCR using the primers RO5 and RO3 (Table 1), which contained the HindIII and XbaI restriction enzyme sites, respectively. After subcloning and sequencing of the FT cDNA, the amplified rolC promoter region was digested with HindIII and XbaI, the 35S promoter of pSM35S::AtFT was cut out with HindIII and XbaI, and the rolC promoter was inserted into the corresponding sites. The obtained vector was designated pSMrolC::AtFT (Figure 1). The green fluorescent protein (GFP) was obtained from Professor Yasuo Niwa, University of Shizuoka, Japan (Niwa et al. 1999). The sGFP (S65T) contained the NcoI restriction enzyme site at the ATG start codon, and AtFT was amplified with the primer pair $\mathrm{tF} 5 \mathrm{X} / \mathrm{tF} 3 \mathrm{~N}$ (Table 1), which contained the $\mathrm{NcoI}$ site at the $3^{\prime}$ end, for in-frame fusion with GFP. After subcloning and sequencing of the AtFT cDNA, AtFT:GFP under the control of the $35 \mathrm{~S}$ or rolC promoter vector was constructed and designated pSM35S::AtFT:GFP or pSMrolC::AtFT:GFP (Figure 1). Transformation of apple was performed in accordance with the method described previously (Wada et al. 2009). Leaflets from cultured shoots of JM2 were infected by Agrobacterium tumefaciens strain LBA4404 bearing each vector. Transformed shoots were selected and grown in vitro on medium supplemented with $50 \mathrm{mg} \mathrm{l}^{-1}$ kanamycin and
$50 \mathrm{mg}^{-1}$ meropenem (Dainippon Sumitomo Pharma Co., Osaka, Japan) over the course of several months. Surviving shoots were cultured on root-induction medium and the rooted shoots were transplanted into sterile soil in a plastic pot. After acclimatization for 3-4 weeks, the transgenic plants were moved to closed greenhouses and grown for several months to 4 years.

\section{Genetic analysis of transformants}

RNA from the transformants was extracted using the CTAB method as described previously (Wada et al. 2002). Reverse transcription PCR (RT-PCR) (Toyobo, Tokyo, Japan) reactions with random primers $(9 \mathrm{nt})$ were performed using $1.0 \mu \mathrm{g}$ isolated RNA as template, and AtFT transcripts were identified using a sense primer, $\mathrm{tF} 5$, and an antisense primer, $\mathrm{tF} 3$ (Table 1). The thermal cycle program was as follows: $95^{\circ} \mathrm{C}$ for $10 \mathrm{~min}$, followed by 35 cycles of $94^{\circ} \mathrm{C}$ for $30 \mathrm{~s}, 60^{\circ} \mathrm{C}$ for $30 \mathrm{~s}$, and $72^{\circ} \mathrm{C}$ for $1 \mathrm{~min}$. After PCR amplification, the products were electrophoresed in $1.5 \%$ agarose gel and visualized by staining with ethidium bromide. Northern analysis was carried out in accordance with the method described previously (Wada 2008). The RNA isolated from each transformant leaf was electrophoresed in a $1.0 \%$ agarose gel and then blotted onto a nylon membrane. The blotted membrane was hybridized with DIG-labeled RNA of the full AtFT coding region in DIG Easy HYB solution (Roche Diagnostics, Mannheim, Germany) at $68^{\circ} \mathrm{C}$ for about $16 \mathrm{~h}$. After hybridization, the filter was rinsed twice in $2 \times$ SSC with $0.1 \%(\mathrm{w} / \mathrm{v})$ SDS at room temperature for $10 \mathrm{~min}$ each, then washed twice in $0.5 \times \mathrm{SSC}$ with $0.1 \%(\mathrm{w} / \mathrm{v})$ SDS at $68^{\circ} \mathrm{C}$ for $10 \mathrm{~min}$ each. Detection of DIG was performed in accordance with the reagent manufacturer's instructions (Roche Diagnostics). Chemiluminescent signals were detected with CDP-STAR (Roche Diagnostics) and visualized with a LAS1000 image analyzer (Fuji Film, Tokyo, Japan).

Transformants that carried GFP were grown in plastic boxes and the shoot apex was excised and sectioned ( $20 \mu \mathrm{m}$ thickness) longitudinally with a microslicer DTK-300W (Dosaka EM Co., Kyoto, Japan). GFP fluorescence in the sections was observed with a fluorescence microscope (Leica DMR HC RB- 
5, Germany) and photographed with a Pixera Pro600ES digital CCD camera system (Pixera Corporation, Kanagawa, Japan).

The pollen viability of the transgenic apple lines was tested as described previously (Kotoda et al. 2006).

For quantitative expression analysis, total RNA from flowers of each transformant grown in the greenhouse and twenty-yearold apple cultivar 'Jonathan' trees in the apple research orchard of the Apple Research Division, National Institute of Fruit Tree Science at Morioka city in Japan were extracted as described above. RT-PCR reactions with $1.0 \mu \mathrm{g}$ extracted RNA were performed as described previously (Wada et al. 2009). Specific primers for the endogenous flowering-related genes MdFT1 (AB161112), MdFT2 (AB458504), MdMADS5 (DQ782960), MdMADS13 (AJ251116), MdMADS-NB (AB370211), and AFL2 (AB056159) were used for real-time RT-PCR analysis (Table 1) with the Power SYBR Green Master Mix (Applied Biosystems Japan, Tokyo, Japan). The apple ubiquitin gene (MdUBQ) was used as an internal standard for normalization (Takos et al. 2006).

\section{Results and discussion}

\section{Flower induction by pSM35S::AtFT}

The introduction of pSM35S::AtFT by Agrobacteriummediated transfection was performed with 550 excised leaflets from the apple rootstock 'JM2.' Twenty-two kanamycin-resistant shoots were obtained, of which three shoots developed an inflorescence and floral buds (Figure 2A) 3-4 months after transformation. The inflorescence originated directly from callus and carried many small floral buds, which in length and width were less than $5 \mathrm{~mm}$, but none attained anthesis in vitro. The bud color changed from green to dark brown after 2-3 weeks and finally wilted and died (Figure 2C: arrow head). Newly developed green shoots originated from callus or leaf axils of the original shoot (Figure 2C: arrows), but the three lines that produced floral buds did not show further vegetative growth and eventually died. The explants were subcultured on fresh culture medium and appropriate trimming of callus and shoots were ineffective for maintenance of both vegetative and reproductive growth.

The small floral buds were cut longitudinally and opened, which revealed the presence of immature floral organs (Figure 2B). Small sepals, petals and stamens were distinguishable. The sepals bore many trichomes on their outer (abaxial) surface. The greenish, thin petals showed distinct venation, and short filaments with immature pale-green anthers were detectable. However, no pistils and ovules were visible. All floral organs were much smaller than normally developed organs of apple flowers, but the inflorescence showed the normal apple inflorescence architecture. These results indicated that $A t F T$ promotes the transition from vegetative to reproductive growth in apple, but the promotive effect was insufficient to induce development

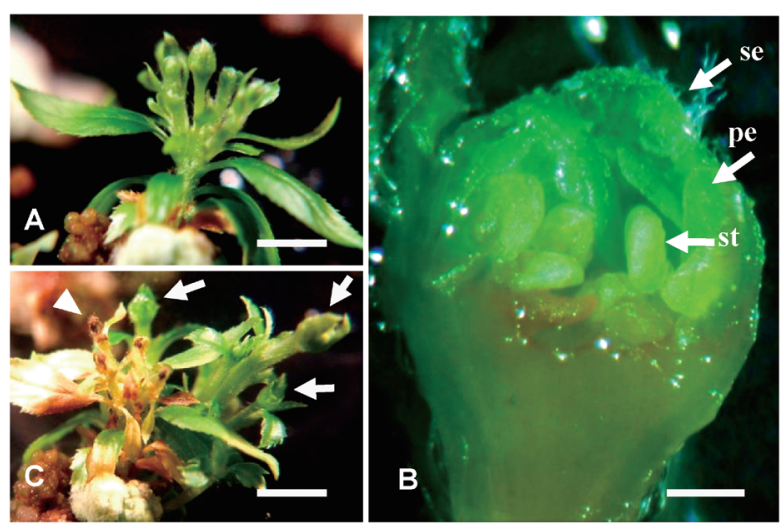

Figure 2. Inflorescence formation in pSM35S::AtFT transgenic apple. (A) A three-month-old shoot in vitro after transformation. (B) Longitudinal section of a floral bud from (A). Arrows indicate immature floral organs. Se; sepal, Pe; petal, St; stamen. (C) A transgenic shoot four months after transformation. The arrow head indicates a wilted, necrotic floral bud. Arrows indicate newly developed floral buds. Scale bar $=1 \mathrm{~cm}(\mathrm{~A}, \mathrm{C}), 1 \mathrm{~mm}(\mathrm{~B})$.

of gynoecia. As mentioned above, three independent lines that overexpressed AtFT showed identically extreme precocious flowering. This finding suggested that AtFT driven by the $35 \mathrm{~S}$ promoter strongly induced flower induction in apple.

\section{Flower induction by pSM35S::AtFT:GFP}

It was predicted that suppression of vegetative growth by $35 \mathrm{~S}:$ :AtFT in transgenic apple would be reduced by insertion of a chimeric gene fused with GFP or by expression control. The GFP protein is generally used as a reporter to detect the target protein. However, AtFT fused with GFP attenuated the induction of flowering in Arabidopsis (Corbesier et al. 2007). To reduce extreme flowering induction by 35S::AtFT in transgenic apple, an AtFT:GFP fusion gene vector was constructed (Figure 1). Introduction of pSM35S::AtFT:GFP was performed with 3,400 excised leaflets of 'JM2.' Nineteen kanamycinresistant shoots were obtained, but no transformants showed flower induction in vitro or when grown in a pot after acclimatization. The transformants grown in a pot failed to bloom in the greenhouse for four years.

Expression of the introduced AtFT gene was detected by northern analysis (Figure 3). Each transformant expressed AtFT or AtFT:GFP RNA of the expected length ( 0.9 and $1.6 \mathrm{~kb}$, respectively). This analysis showed that the $35 \mathrm{~S}$ promoter lead to much higher transcription activity compared with the rolC promoter. Fluorescence from GFP in the transformants was observed in each section (Figures 4B-D). Transformants that expressed the GFP driven by the $35 \mathrm{~S}$ promoter (Figure 4C) showed GFP fluorescence in all tissues of the shoot. Conversely, fluorescence from GFP driven by the rolC promoter was localized in vascular tissues (Figures $4 \mathrm{~B}$, D). Both rolC::GFP and rolC::AtFT:GFP proteins were 
expressed specifically in vascular tissues. The localization patterns were indicated to be almost identical. Highmagnification images showed that fluorescence was localized in sieve tube cells (Figures 4E, F). Similarly, transverse sections of the petiole from rolC::AtFT:GFP transformants indicated that the fluorescence was localized to the phloem (Figure 4G). Localization of GUS protein driven by the rolC promoter in apple cultivar 'Greensleeves' (Gittins et al. 2003) was identical to that of GFP in the present experiments. In contrast,

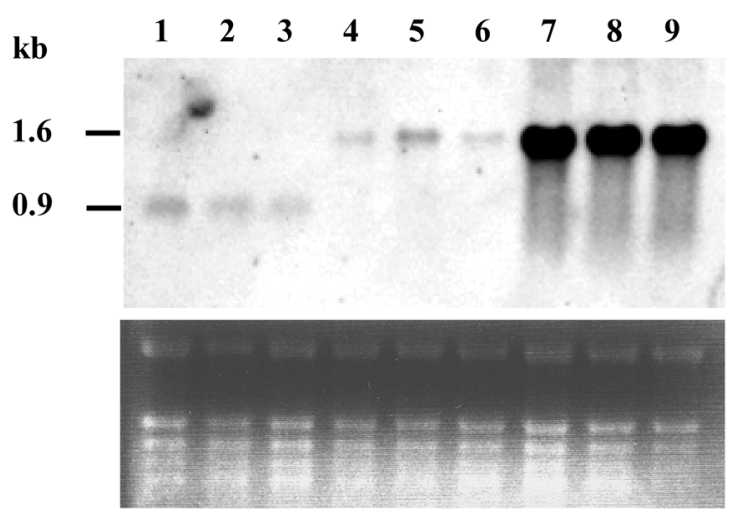

Figure 3. Northern analysis of AtFT expression in transgenic apples. Lanes 1 to 3: prolC::AtFT; lanes 4 to 6: prolC::AtFT:GFP; and lanes 7 to 9: 35S::AtFT:GFP. The numbers to the left of the figure indicate RNA size, $\mathrm{kb}=$ kilobase. The lower panel shows a gel stained with ethidium bromide before blotting. accumulation of the AtFT:GFP fusion protein driven by the $35 \mathrm{~S}$ promoter was observed in all cells of the shoot. These results indicated that the GFP fusion proteins were stably expressed in apple tissues. However, the chimeric AtFT protein was incapable of inducing precocious flowering in apple. We hypothesize that the AtFT:GFP fusion protein is unable to interact with intrinsic proteins that control the apple flowering induction process (Abe et al. 2005; Taoka et al. 2011).

\section{Moderate flowering induction by pSMro/C::AtFT}

The pSMrolC::AtFT construct was introduced into 2,675 excised leaflets of 'JM2' and 20 kanamycin-resistant shoots were obtained. Eleven of the transgenic shoots bloomed in vitro 4-8 months after transformation (Figure 5). On culture medium, the shoots produced flowers, which were smaller than flowers of nontransformed apple (Figure 5A). Sepals, petals, short stamens and pistils were observable in the flowers, but the numbers of each floral part differed from that of normal flowers. After acclimatization, the transgenic apples were transplanted into pots and grown in a culture room or greenhouse. All lines showed perpetual flowering under artificial light or natural sunlight in the greenhouse (Figures 5B, D-F), and they did not show any chilling requirement. The potted transgenic plants developed flowers of normal size, which contained sepals, petals, stamens and, in most lines, no pistils
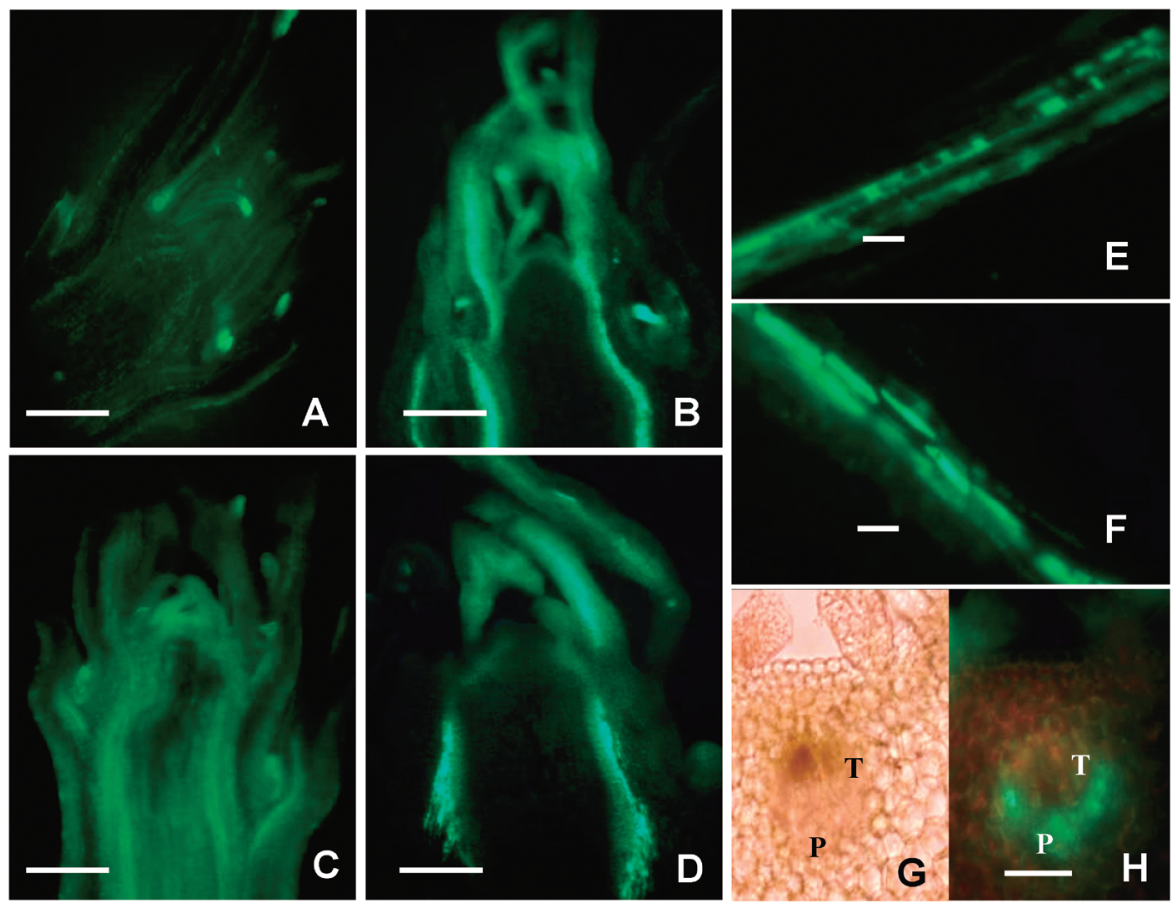

Figure 4. Detection of GFP protein fluorescence in transgenic apples. (A-D) Longitudinal sections of a shoot apex of (A) 'JM2' (non-transformed control), (B) prolC::GFP, (C) 35S::AtFT:GFP, (D) prolC::AtFT:GFP. (E) High-magnification image of prolC::GFP, showing GFP fluorescence in the phloem. (F) High-magnification image of prolC::AtFT:GFP, showing GFP fluorescence in the phloem. (G, H) Transverse sections of a leaf petiole of rolC::AtFT:GFP; bright-field $(\mathrm{G})$ and fluorescence $(\mathrm{H})$ images of the same section are shown. T; tracheary element. P; phloem. Scale bar=500 $\mu \mathrm{m}$ (A-D), $25 \mu \mathrm{m}(\mathrm{E}-\mathrm{H})$. 

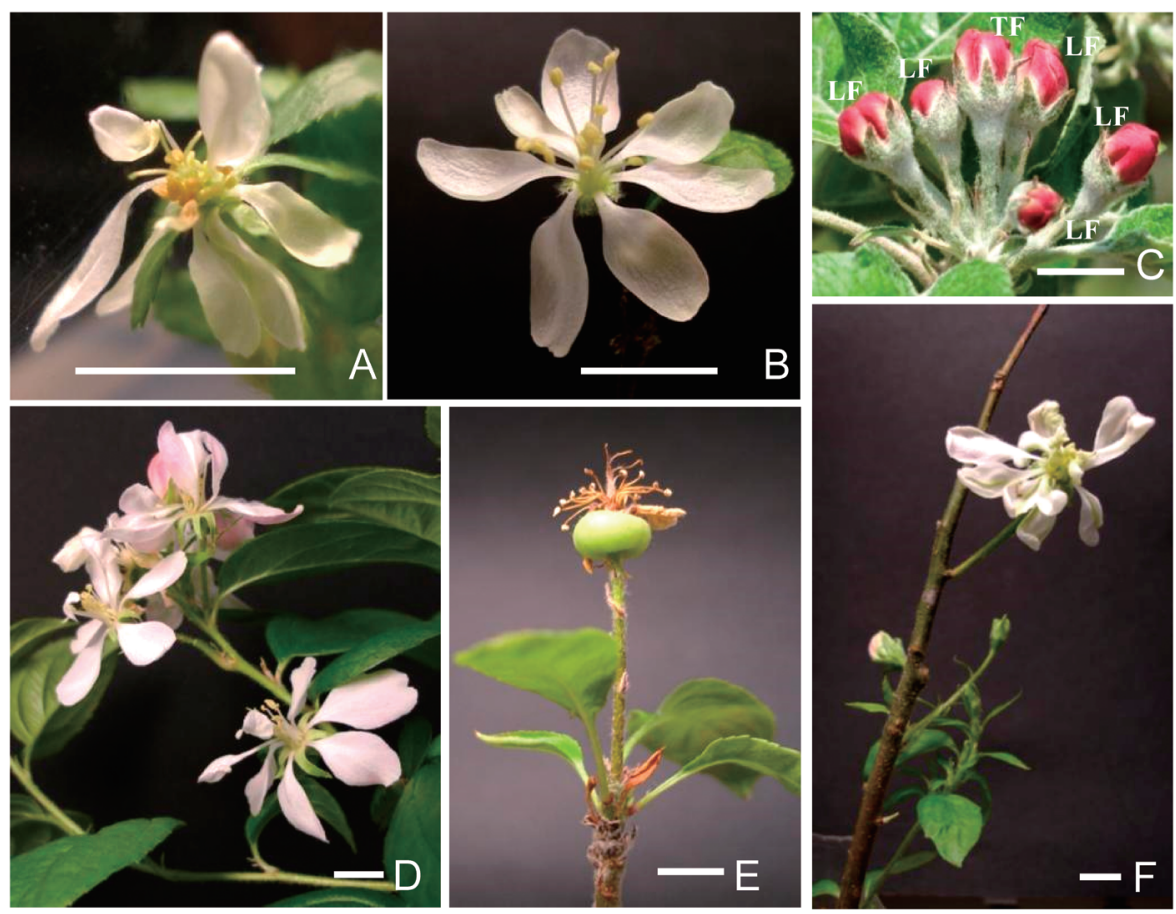

Figure 5. Flower formation in prolC::AtFT transgenic apple. (A) A cultured shoot formed flowers in vitro six months after transformation. (B) A flower from a plant that was acclimatized and transplanted to a pot, two years after transformation. (C) An inflorescence of apple cultivar 'Jonathan' on 16 May. (D) An inflorescence of prolC::AtFT transgenic apple. (E) An immature parthenocarpic fruit from prolC::AtFT transgenic apple. (F) Flower formation directly from the stem of prolC::AtFT transgenic apple. TF: terminal flower. LF: lateral flower. Scale bar $=1.0 \mathrm{~cm}$.

(Figure 5B). Occasional flowers contained one to three styles but no ovaries (Table 2). Expression of AtFT under the control of the rolC promoter was restricted to the phloem. Both rolC::GFP and rolC::AtFT:GFP transformants accumulated GFP protein in the phloem (Figure 4), and weak GFP fluorescence was observed in the vicinity of the meristems (Figures $4 \mathrm{~B}, \mathrm{D}$ ). We hypothesize that AtFT protein expressed in the phloem was transported to the meristems or that leaky expression in the meristem might occur. In both cases, the results suggested that a small amount of AtFT protein in the meristem caused the moderate flowering induction. These results indicated that the amount of AtFT protein in the meristem plays a pivotal role in the determination of vegetative or reproductive development. In the case of MdFT1, 35S::MdFT1 was unable to induce flowering in apple. MdFT1 expression under the control of the 35S promoter plus an omega factor is needed for precocious flowering induction in apple (Kotoda et al. 2010). These findings suggest that stable translation by a sigma factor and accumulation of MdFT proteins in the meristem is crucial for precocious flowering in transgenic apple. These results indicated that MdFT1 from apple and AtFT from A. thaliana have contrasting effects on flower induction in apple. It appears that the expression level of $M d F T 1$ must be higher than that of AtFT to be effective. $M d F T 2$ transgenic apple showed the same traits as MdFT1 transformants. It is suggested that a possible suppressor might have prevented MdFT function in the transgenic apples, but might have no effect on AtFT protein. Thus a lower expression level of AtFT would be able to induce moderate flowering in apple.

\section{Characterization of pSMrolC::AtFT transgenic apple}

In pSMrolC::AtFT apple transformants, the numbers of each floral part, especially petals and stamens, differed from that of normal flowers. Normal apple flowers were composed of five sepals, five petals, approximately 20 stamens, and five pistils (see data for 'Fuji' and 'Jonathan' cultivars in Table 2). However, the flowers of all pSMrolC::AtFT transgenic apple lines contained more petals and fewer stamens than flowers from nontransformed apple cultivars (Table 2). Furthermore, pistils were rarely observed and thus ovules, ovaries and styles were rarely formed. Occasionally, tiny thin pistils were observed but these usually never contained ovules. The transgenic apple flowers by $35 \mathrm{~S} \Omega:: \mathrm{MdFT} 1$ had same disorder of flower organs (Table 2).

Abnormality in the number of floral parts of MdFToverexpressing transgenic apples has been reported previously (Kotoda et al. 2010; Tränkner et al. 2010; Yamagishi et al. 2011). This finding indicated that FT overexpression was able to cause early flowering in apple, but was unable to maintain the induction of floral organ development. Apple cultivars produce a determinate inflorescence, which consists of 4-8 flowers with a terminal flower (TF) and lateral flowers (LF), located in 
Table 2. Numbers of each floral part per flower in transgenic apples.

\begin{tabular}{|c|c|c|c|c|c|}
\hline Line/cultivar & Sepal & Petal & Stamen & Carpel & $n$ \\
\hline \multicolumn{6}{|l|}{ rolC::AtFT } \\
\hline 39 & $5.6 \pm 0.59$ & $6.38 \pm 1.5$ & $13.8 \pm 3.6$ & $0.7 \pm 1.2$ & 16 \\
\hline 66 & $5.0 \pm 0.4$ & $7.7 \pm 2.1$ & $12.7 \pm 3.6$ & 0 & 13 \\
\hline 201 & $5.3 \pm 0.8$ & $6.5 \pm 1.76$ & $13.0 \pm 1.1$ & $0.3 \pm 0.5$ & 6 \\
\hline 402 & $5.28 \pm 0.7$ & $7.35 \pm 1.59$ & $14.4 \pm 3.3$ & $0.3 \pm 0.85$ & 14 \\
\hline 421 & $5.9 \pm 1.16$ & $7.65 \pm 1.84$ & $13.2 \pm 3.4$ & $0.4 \pm 1.35$ & 20 \\
\hline \multicolumn{6}{|l|}{$35 \mathrm{~S} \Omega:: \mathrm{MdFT} 1$} \\
\hline 71 & $5.3 \pm 0.65$ & $8.58 \pm 3.3$ & $16.0 \pm 3.89$ & $1.1 \pm 1.8$ & 12 \\
\hline 72 & $5.2 \pm 0.44$ & $7.82 \pm 1.8$ & $17.8 \pm 3.1$ & $0.3 \pm 0.9$ & 23 \\
\hline $73 a$ & $5.1 \pm 0.33$ & $9.0 \pm 2.2$ & $16.1 \pm 4.1$ & $0.3 \pm 1.0$ & 9 \\
\hline \multicolumn{6}{|l|}{ Orchard Tree } \\
\hline Fuji & $5.00 \pm 0.2$ & $5.00 \pm 0$ & $19.8 \pm 0.20$ & $5.00 \pm 0.2$ & 20 \\
\hline Jonathan & $5.00 \pm 0.3$ & $5.00 \pm 0$ & $20.0 \pm 0.20$ & $5.00 \pm 0$ & 20 \\
\hline
\end{tabular}

Table 3. Number of flowers produced by transgenic apple.

\begin{tabular}{|c|c|c|c|c|}
\hline Line/cultivar & Period (months) & Flowers & Plants & Flowers/plant/year \\
\hline \multicolumn{5}{|l|}{ 35S $\Omega:: M d F T 1$} \\
\hline 71 & 9 & 6 & 7 & 1.14 \\
\hline 72 & 8 & 20 & 18 & 1.67 \\
\hline $73 a$ & 14 & 10 & 11 & 0.78 \\
\hline $73 b$ & 13 & 3 & 10 & 0.32 \\
\hline \multicolumn{5}{|l|}{ prolC::AtFT } \\
\hline 39 & 19 & 38 & 2 & 12.0 \\
\hline 66 & 19 & 39 & 17 & 1.45 \\
\hline 421 & 19 & 80 & 22 & 2.29 \\
\hline
\end{tabular}

close proximity to the shoot apex (Figure 5C). However, most inflorescences of the transgenic apple lines grown in pots showed a different inflorescence architecture. The internode between each flower was longer and the flower number per inflorescence was reduced (Figure 5D). In another case, solitary flowers with a longer pedicel developed directly from the stem (Figure 5F) (Foster et al. 2003; Pratt 1988).

Some flowers produced parthenocarpic fruits (Figure 5E), which were smaller than pollinated fruits. The frequency of parthenocarpy was $0-19 \%$ in four pSMrolC::AtFT transgenic apple lines. Parthenocarpy was observed also in transgenic apple lines that overexpressed MdFT1. The pollen viability of pSMrolC::AtFT transgenic apple lines was tested. Pollen germination was rarely observed and controlled pollinations with the pollen resulted in no fruit set (data not shown). The pSMrolC::AtFT transgenic apple lines often produced a higher number of flowers than 35S $\Omega::$ MdFT1 transgenic lines (Table 3). The pSMrolC::AtFT transgenic lines developed 1.45 to 12.0 flowers per pot per year in the culture room under a $16 \mathrm{~h} / 8 \mathrm{~h}$ (light/dark) photoperiod, whereas the $35 \mathrm{~S} \Omega:: \mathrm{MdFT} 1$ transgenic lines developed 0.32 to 1.67 flowers per pot per year under the same growing conditions. Thus AtFT functioned more effectively than $M d F T$ for flowering induction in apple. The apple genome contains two FT genes, MdFT1 and MdFT2. The expression pattern of each gene is completely different during floral initiation and flower development (Kotoda et al. 2010). Thus, the two MdFT genes are indicated to have distinct functions in flowering. MdFT1 is a possible inducer of flowering, whereas MdFT2 might be necessary for floral development and fruit formation given that transgenic apple lines that overexpressed MdFT2 developed flowers that were more similar to normal flowers than that of MdFT1-overexpressing transgenic apple lines (data not shown).

\section{Expression analysis of apple flower genes influenced by AtFT}

Transgenic apple lines developed malformed flowers (Table 2, Figure 5). This finding suggested that pSMrolC::AtFT might affect expression of genes related to floral organ identity in apple. Consequently, the expression patterns of six flowering-related genes in flowers of each transgenic apple line were determined by quantitative RT-PCR analysis (Table 1). MdFT1 and MdFT2 are FT homologs from apple, and MdMADS5 is an APETALA1 homolog (Kotoda et al. 2002), which is believed to function as a possible class A gene in apple. MdMADS13 (van der Linden et al. 2002) is an APETALA3 homolog, which is thought to function as a class B gene in apple. MdMADS-NB was isolated from apple flowers at our research station and is an AGAMOUS homolog in apple, which is considered to 

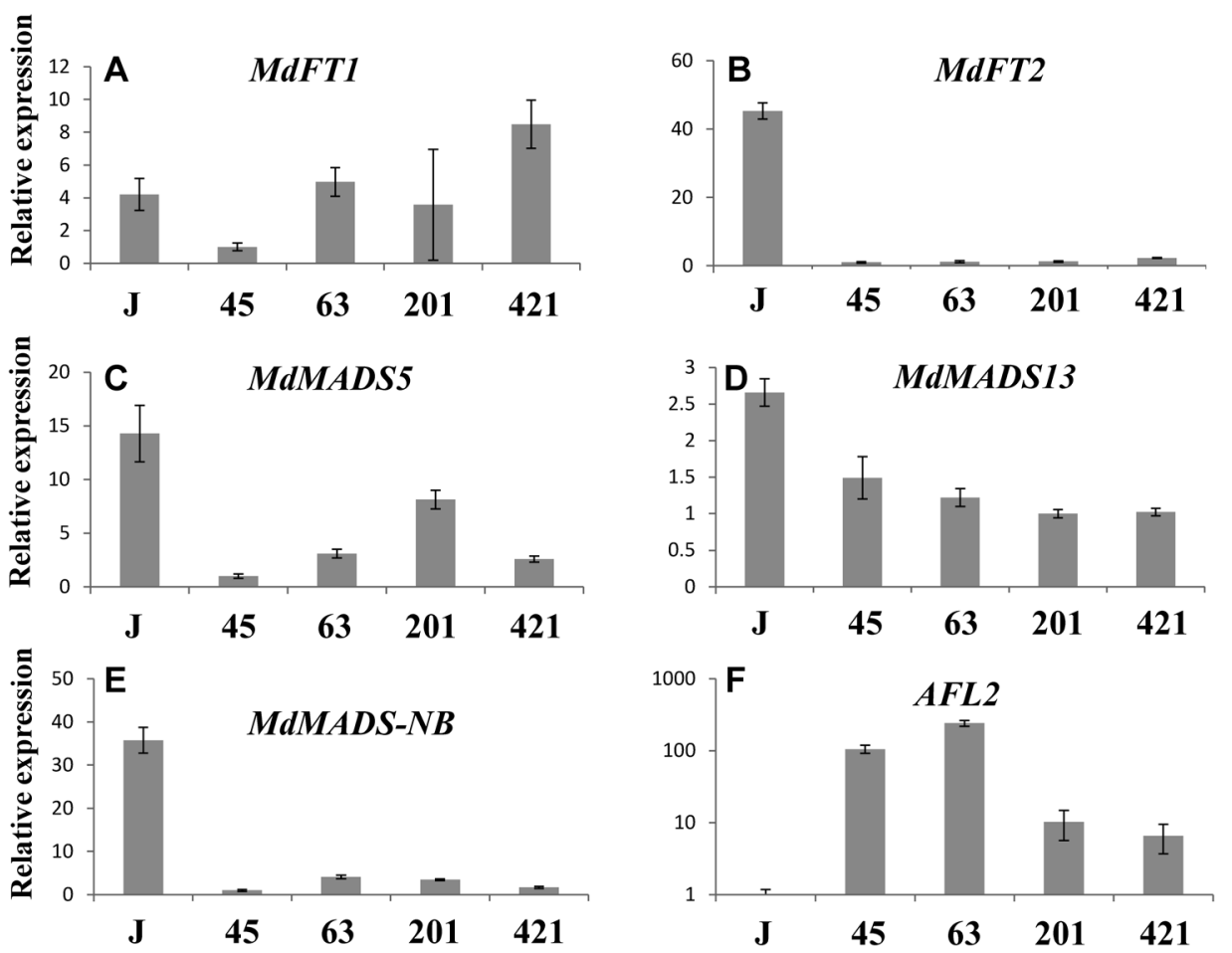

Figure 6. Quantitative expression analysis of flowering-related genes in AtFT transgenic apple lines. Expression of MdFT1 (A), MdFT2 (B), MdMADS5 (C), MdMADS13 (D), MdMADS-NB (E) and AFL2 (F) in the transgenic apple lines (prolC::AtFT 45, 63, 201, 421) and apple cultivar 'Jonathan' (J; control) were quantified by real-time PCR. All transgenic lines showed perpetual flowering. In F, the expression level is presented on a logarithmic scale. The gene-specific primer sets used are listed in Table 1. Transcription levels were normalized against apple ubiquitin. All values are means of results from three replicates, error bars indicate the S.D.

function as a class $\mathrm{C}$ gene. AFL2 is a $L E A F Y$ ortholog in apple (Flachowsky et al. 2010; Wada et al. 2002, 2007, 2009), which functions in integration of flowering signals.

MdFT1 and MdFT2 showed contrasting expression patterns (Figures 6A, B). The expression level of MdFT1 in four pSMrolC::AtFT transgenic lines was not affected compared with expression in 'Jonathan' apple, whereas MdFT2 expression was strongly suppressed in all four transgenic lines. In addition, the expression patterns of MdFT1 and MdFT2 during floral development were distinct (Kotoda et al. 2010). The MdFT1 expression level was high during floral differentiation in summer, whereas the MdFT2 expression level increased largely in the blooming period (in spring of the following year). These differences suggest the two genes play distinct roles in the flowering process. The suppression of MdFT2 seemed to reflect the competence of the extrinsic AtFT. MdMADS5 and MdMADS13 (Figures 6C, D) were more weakly expressed in the four transgenic apple lines than in the control, although in some lines the expression level was about half that of the control. MdMADS-NB expression was suppressed strongly in the four lines similar to MdFT2 (Figure 6E). These genes for floral organ identity showed a decreased level of expression, which might explain the abnormal number of floral organs. In particular, the suppression of MdMADS-NB might result in the absence of pistils. For an improved understanding of the molecular mechanisms underlying flowering in apple, additional information on floral organ identity genes in apple is required.

In contrast, the AFL2 expression level was markedly higher than that of 'Jonathan' apple (Figure 6F). The transgenic lines expressed AFL2 at a level about 10-300 times higher than that of the control. It was unclear if the considerably increased expression of AFL2 was affected by AtFT directly or indirectly. AFL2 was expressed in the floral organs of apple, so excess AFL2 might affect the floral organ number and shape (Mimida et al. 2011; Wada et al. 2002). However, the AFL2-overexpressing transgenic apple trees grew for almost 10 years without developing flowers (data not shown). Overexpression in apple of $L F Y$ from $A$. thaliana does not induce precocious flowering and instead affects vegetative growth (Flachowsky et al. 2010). These results suggest that AFL2 is not involved in the integration of flowering signals.

It is well known that $F T$ genes and proteins are highly conserved among plant species. However, the present study has revealed functional differences between Arabidopsis FT (AtFT) and apple MdFT1 or MdFT2. The results indicate that this reflects not only the difference of FT molecules, but also differences in FT signal reception. Further research is needed to improve understanding of 
the flowering mechanism in apple.

\section{References}

Abe M, Kobayashi M, Yamamoto S, Daimon Y, Yamaguchi A, Ikeda Y, Ichinoki H, Notaguchi M, Goto K, Araki T (2005) FD, a bZIP protein mediating signals from the floral pathway integrator FT at the shoot apex. Science 309: 1052-1056

Böhlenius H, Tao H, Charbonnel-Campaa L, Brunner AM, Jansson S, Strauss S, Nilsson O (2006) CO/FT regulatory module controls timing of flowering and seasonal growth cessation in trees. Science 312: 1040-1043

Chen Y, Jiang H, Thammannagowda S, Liang H, Wilde HD (2013) Characterization of peach TFL1 and comparison with FT/TFL1 gene families of the Rosaceae. J Am Soc Hortic Sci 138: 12-17

Corbesier L, Vincent C, Jang S, Fornara F, Fan Q, Searle I, Giakountis A, Farrona S, Gissot L, Turnbull C, et al. (2007) FT protein movement contributes to long-distance signaling in floral induction of Arabidopsis. Science 316: 1030-1033

Cremer F, Lönnig WE, Saedler H, Huijser P (2001) The delayed terminal flower phenotype is caused by a conditional mutation in the CENTRORADIALIS gene of snapdragon. Plant Physiol 126: 1031-1041

Endo T, Shimada T, Fujii H, Kobayashi Y, Araki T, Omura M (2005) Ectopic expression of an FT homologu from Citrus confers an early flowering phenotype on trifoliate orange (Poncirus trifoliata L. Raf.). Transgenic Res 14: 703-712

Flachowsky H, Hättasch C, Höfer M, Peil A, Hanke MV (2010) Overexpression of $L E A F Y$ in apple leads to a columnar phenotype with shorter internodes. Planta 231: 251-263

Flachowsky H, Szankowsky I, Waidmann S, Peil A, Tränkner C, Hanke MV (2012) The MdTFL1 gene of apple (Malus $\times$ domestica Borkh.) reduces vegetative growth and generation time. Tree Physiol 32: 1288-1301

Foster T, Johnston R, Seleznyova A (2003) A morphological and quantitative characterization of early floral development in apple (Malus $\times$ domestica Borkh.). Ann Bot (Lond) 92: 199-206

Gittins JR, Pellny TK, Biricolti S, Hiles ER, Passey AJ, James DJ (2003) Transgenic expression in the vegetative tissues of apple driven by the vascular-specific rolC and CoYMV promoters. Transgenic Res 12: 391-402

Hanano S, Goto K (2011) Arabidopsis TERMINAL FLOWER1 is involved in the regulation of flowering time and inflorescence development through transcriptional repression. Plant Cell 23: 3172-3184

Hsu CY, Liu Y, Luthe DS, Yuccer C (2006) Poplar FT2 shortens the juvenile phase and promotes seasonal flowering. Plant Cell 18: 1846-1861

Iwata $\mathrm{H}$, Gaston A, Remay A, Thouroude T, Jeauffre J, Kawamura K, Oyant LHS, Araki T, Denoyes B, Foucher F (2012) The TFL1 homologue $K S N$ is a regulator of continuous flowering in rose and strawberry. Plant J 69: 116-125

Kotoda N, Hayashi H, Suzuki M, Igarashi M, Hatsuyama Y, Kidou S, Igasaki T, Nishiguchi M, Yano Y, Shimizu T, et al. (2010) Molecular characterization of FLOWERING LOCUS T-like genes of apple (Malus $\times$ domestica Borkh.). Plant Cell Physiol 51: 561-577

Kotoda N, Takahashi S, Iwanami H, Abe K (2006) Antisense expression of MdTFL1, a TFL1-like gene, reduces the juvenile phase in apple. J Am Soc Hortic Sci 131: 74-81

Kotoda N, Wada M (2005) MdTFL1, a TFL1-like gene of apple, retards the transition from the vegetative to reproductive phase in transgenic Arabidopsis. Plant Sci 168: 95-104

Kotoda N, Wada M, Kusaba S, Kano-Murakami Y, Masuda T, Soejima J (2002) Overexpression of MdMADS5, an APETALA1like gene of apple, causes early flowering in transgenic Arabidopsis. Plant Sci 162: 679-687

Lifschitz E, Eshed Y (2006) Universal florigenic siganals triggered by FT homologues regulate growth and flowering cycles in perennial day-neutral tomato. J Exp Bot 57: 3405-3414

Matsuda N, Ikeda K, Kurosaka M, Takashina T, Isuzugawa K, Endo T, Omura M (2009) Early flowering phenotype in transgenic pears (Pyrus communis L.) expressing the CiFT gene. J Jpn Soc Hortic Sci 78: 410-416

Matsuki R, Onodera H, Yamauchi T, Uchimiya H (1989) Tissuespecific expression of the rolC promoter of the Ri plasmid in transgenic rice plants. Mol Gen Genet 220: 12-16

Mimida N, Kotoda N, Ueda T, Igarashi M, Hatsuyama Y, Iwanami H, Moriya S, Abe K (2009) Four TFL1/CEN-like genes on distinct linkage groups show different expression patterns to regukate vegetative and reproductive development in apple (Malus $\times$ domestica Borkh.). Plant Cell Physiol 50: 394-412

Mimida N, Li J, Zhang C, Moriya S, Moriya-Tanaka Y, Iwanami H, Honda C, Oshino H, Takagishi K, Suzuki A, et al. (2012) Divergence of TERMINAL FLOWER1-like genes in Rosaceae. Biol Plant 56: 465-472

Mimida N, Ureshino A, Tanaka N, Shigeta N, Sato N, MoriyaTanaka Y, Iwanami H, Honda C, Suzuki A, Komori S, et al. (2011) Expression patterns of several floral genes during flower initiation in the apical buds of apple (Malus $\times$ domestica Borkh.) revealed by in situ hybridaization. Plant Cell Rep 30: 1485-1492

Niwa Y, Hirano T, Yoshimoto K, Shimizu M, Kobayashi H (1999) Non-invasive quantitative detection and applications of nontoxic, S65T-type green fluorescent protein in living plants. Plant J 18: 455-463

Pratt C (1988) Apple flower and fruit: morphology and anatomy. Hortic Rev (Am Soc Hortic Sci) 10: 273-307

Pin PA, Nilsson O (2012) The multifaceted roles of FLOWERING LOCUS $\mathrm{T}$ in plant development. Plant Cell Environ 35: 1742-1755

Pnueli L, Carmel-Goren L, Hareven D, Gutfinger T, Alvalez J, Ganal M, Zamir D, Lifschitz E (1998) The SELF-PRUNING gene of tomato regulates vegetative to reproductive switching of sympodial meristems and is the ortholog of CEN and TFL1. Development 125: 1979-1989

Srinivasan C, Dardick C, Callahan A, Scorza R (2012) Plum (Prunus domestica) trees transformed with poplar FT1 results in altered architecture, dormancy requirement, and continuous flowering. PLoS ONE 7: 1-11

Sugaya S, Uchimiya H (1992) Deletion analysis of the $5^{\prime}$-upstream region of the Agrobacterium rhizogenes Ri plasmid rolC gene required for tissue-specific expression. Plant Physiol 99: 464-467

Takos AM, Ubi BE, Robinson SP, Walker AR (2006) Condensed tannin biosynthesis genes are regulated separately from other flavonoid biosynthesis genes in apple fruit skin. Plant Sci 170: 487-499

Tamaki S, Matsuo S, Wong HL, Yokoi S, Shimamoto K (2007) $\mathrm{Hd} 3 \mathrm{a}$ protein is a mobile flowering signal in rice. Science 316 : 1033-1036

Taoka K, Ohki I, Tsuji H, Furuita K, Hayashi K, Yanase T, Yamaguchi M, Nakashima C, Purwestri YA, Tamaki S, et al. (2011) 14-3-3proteins act as intracellular receptors for rice Hd3a florigen. Nature 476: 332-335

Tränkner C, Lehmann S, Hoenicka H, Hanke MV, Fladung M, 
Lenhardt D, Dunemann F, Gau A, Schlangen K, Malnoy M, et al. (2010) Over-expression of FT-homologous gene of apple induces early flowering in annual and perennial plants. Planta 232: 1309-1324

van der Linden CG, Vosman B, Smulders MJM (2002) Cloning and characterization of four apple MADS box genes isolated from vegetative tissue. J Exp Bot 53: 1025-1036

Wada M (2008) Gene expression in parthenocarpic apple with floral organ mutation. Gamma Field Symposia 47: 59-66

Wada M, Cao QF, Kotoda N, Soejima J, Masuda T (2002) Apple has two orthologues of FLORICAULA/LEAFY involved in flowering. Plant Mol Biol 49: 567-577

Wada M, Ureshino A, Cao QF, Bessho H (2007) Genomic varieties of apple AFL genes. Plant Sci 173: 559-566
Wada M, Ureshino A, Tanaka N, Komori S, Takahashi S, Kudo K, Bessho H (2009) Anatomical analysis by two approaches ensures the promoter activities of apple AFL genes. J Jpn Soc Hortic Sci 78: 32-39

Weigel D, Nillson O (1995) A developmental switch sufficient for flower initiation in diverse plants. Nature 377: 495-500

Yamagishi N, Sasaki S, Yamagata K, Komori S, Nagase M, Wada M, Yamamoto T, Yoshikawa N (2011) Promotion of flowering and reduction of a generation time in apple seedlings by ectopical expression of the Arabidopsis thaliana FT gene using the Apple latent spherical virus vector. Plant Mol Biol 75: 193-204

Yamashita S, Ichikawa H, Ito Y, Ohashi Y (1995) Development of new binary vectors stably maintained in Agrobacterium and their utilization to plant transformation. Breed Sci 45(suppl.1): 56 